Research Paper

\title{
Flexural Analysis of Functionally Graded thin Walled Beams
}

\author{
SB SINGH ${ }^{1}$, HIMANSHU CHAWLA ${ }^{2}$ and ADITYA NARKHEDE ${ }^{3}$ \\ ${ }^{1}$ Professor of Civil Engineering, BITS Pilani 333 031, India \\ ${ }^{2}$ Assistant Professor, Thapar Institute of Engineering and Technology, Patiala, India \\ ${ }^{3}$ Civil Engineering Department, BITS Pilani 333 031, India
}

(Received on 14 March 2018; Revised on 23 August 2018; Accepted on 24 August 2018)

\begin{abstract}
In this paper, an analytical model has been presented for study of flexural response of functionally graded thin walled beam incorporating first order shear deformation theory and Vlasov's theory for thin walled beam. The material properties are varied along the depth direction according to the power law distribution of volume fraction of mild steel and alumina. Numerical results for functionally graded thin beams under uniformly distributed vertical loading (for various span to depth ratio) have also been presented.
\end{abstract}

Keywords: ABAQUS; MATLAB; Functionally Graded Beam; Flexural Response; Thin Composite Structure; Timoshenko Beam Theory; Vlasov's Thin Walled Beam Theory

\section{Significance Statement}

The study presented provides an insight on the behavior of thin walled beams, whose material varies along the depth direction according to the power law, under pure flexure. The study incorporates first order shear deformation of the thin beams and hence provides information on the nature of response of thin beams made of functionally graded material whose cross-sectional plane does not remain orthogonal to the longitudinal axis after deformation.

\section{Introduction}

Composite beams consist of two or more materials of different mechanical properties joint together through a mechanical bond and are allowed to deform as a whole. Though having significant application in various fields, they have a major drawback, the stress concentration developed near the mechanical joint of the different materials, induced due to the difference in material properties. Hence a new technique to vary the material properties along the cross-section of the structural element was first initiated by a Japanese scientist in Sendai (Niino et al., 1987) which led to the introduction of a new class of materials known as
Functionally Graded Materials or FGM. Continuous variation of material as shown in Fig. 1 and Fig. 2, eliminates the stress concentrations at the interface layers. In addition, FGMs show high stiffness and strength to weight ratios, high fracture resistance and enhanced thermal properties. Generally, the variations are achieved through volume fraction, angle of lamination, diameter, chemical composition of fibers etc. (Birman, 2014).

The research community for the past decade has shown interest in developing mathematical models and finite elements so as to simulate the static and dynamic response of thick and thin FGM beams, a brief summary of which is given here. Chakraborty et al., (2003) formulated a new exact finite beam element which was used to describe the thermo-elastic behavior for the static, free vibration and wave propagation studies in a beam. The element calculations were based on first-order shear deformation theory. Studies were carried out on bimaterial beam with an infused FGM layer, the results show that the response of FGM infused beam is significantly enhanced from that of individual material beams. The static studies show that the stress

*Authorfor Correspondence: E-mail: sbsinghbits@gmail.com; sbsingh@pilani.bits-pilani.ac.in 


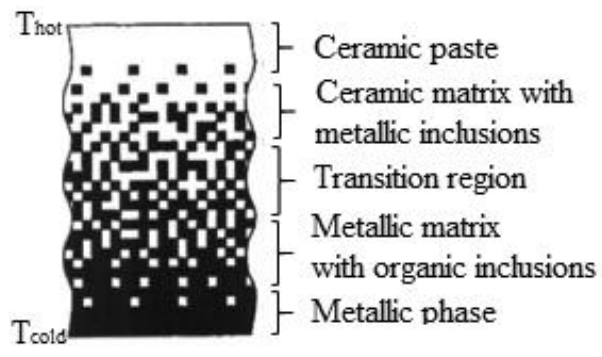

Fig. 1: Functionally graded material, (Filippi et al., 2015)
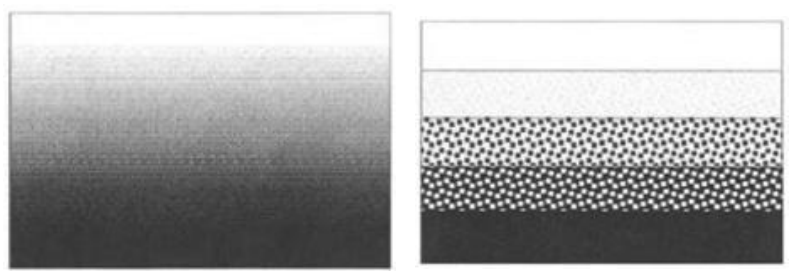

Fig. 2: (A) Continuous variation; (B) Stepped Variation, (Miyamoto et al., 2013)

variation along the depth is smoothened out and the behavior in wave propagation, in general, was found to be average of the two constitutive materials that the beam blends. Li (2008) developed a unified approach to study the static and dynamic behavior of functionally graded beams, the study has included rotary inertia and shear deformation. A single fourthorder partial differential equation was derived, the solution of this partial differential gave all the required physical quantities. Reddy (2000) presented the formulation, finite element model and Navier's solution for functionally graded rectangular plate. The formulation took into account the thermomechanical coupling, time dependency, and the von Karman-type geometric non-linearity. Sankar (2001) obtained elasticity solution for functionally graded simply supported beams, using a beam theory that is similar to the Euler-Bernoulli beam theory. The Poisson's ratio is held constant through the thickness whereas the Young's modulus is varied exponentially along the depth. Aboudi et al. (1999) presented a new higherorder theory for FGM. Kadoli et al. (2008) studied the static behavior of functionally graded beams using higher order shear deformation theory. Strain displacement relation involving the membrane, bending, higher order displacement and transverse shear strain were developed for thick beams. Zenkour, (2006) studied the static behavior of a functionally graded rectangular plate subjected to uniform transverse load and under simply supported
condition.Authors (Filippi et al., 2015 and Das and Sarangi, 2016) studied the static response of FG beams whereas authors (Sina et al., 2009; Thai and Vo, 2012 and Khan et al., 2016) have studied the static and free vibration response of FG beams using various refined finite element theories. Das and Sarangi (2016) presented the modelling of FG beams on ANSYS by considering the material to be consisting of different layers of homogeneous material, in which the volume fraction of different materials was obtained from power law. Li et al. (2013) derived analytical relations between bending solution for FG Timoshenko beams with those of homogeneous EulerBernoulli beam. Chen et al. (2015) studied the elastic buckling and static bending of shear deformable functionally graded porous beams. The study was based on the Timoshenko beam theory. The governing equation for buckling and bending behavior was derived using the Hamilton's principle. The influence of variation of porosity distributions on the structural performance is highlighted, this gave some important insights in the design of porosity to achieve improved bending behavior and buckling resistance. Kim et al. (2016) studied the functionally graded mono-symmetric I and channel section beams modelled on EulerBernoulli beam type and Vlasov's thin walled beam theory. Governing equations were derived by minimum potential energy principle. Furthermore, they considered three kinds of material distribution and compared the results obtained for each case.

Even though thin beams are a type of beam, but their mechanics is quite different from that of the conventional rectangular section. Mitra et al. (2004) developed a new beam element for arbitrary open and closed thin walled beams. The study considered elastic coupling, restraint warping and first-order shear deformation. The beam element was found to be super convergent and free from shear locking. Lee (2005) studied the flexural response of laminated composite I section beam using first-order shear deformation. The study showed that the assumption of normal stress along contour direction is more accurate than that of free strain along the contour. Now if composite materials are used in thin open or closed sections, this adds an irregularity in the beam which leads to a shift of neutral axis and shear center. This shift may lead to a coupling of axial stress, bending stress and torsional stress. Lee and Lee, (2004) developed an analytical model to study the 
flexural-torsional response of laminated composite I section beam using the classical lamination theory. Pandey et al., (1995) presented an analytical study for increasing the lateral buckling strength of composite thin walled open section beam by optimizing the fiber orientation. Shadmehri et al. (2007) presented the static and dynamic response of composite thin walled beams made from single-cell box subjected to coupled flexure and torsion.

The above literature shows that majorly FGM has been worked out for rectangular beams and plates and that thin walled beams are yet to be fully understood for FGM. In general, thin walled beams show cases of warping and torsion-flexural coupling which require additional governing equations to be dealt with. The objective of this paper is to study the flexural response of a thin FGM beam incorporating the first-order shear deformation theory. For doing so, a mathematical model has been made in MATLAB, and the results of which have been compared to the results obtained from ABAQUS/CAE. The paper has been divided into various sections which discuss the kinematics of the model: the constitutive relation, governing equation and one example of transverse loading has been presented to show the beam behavior.

\section{Material Properties}

The material properties are varied continuously throughout the depth of the beam (as in Fig. 2(a)). The top most layer being ceramic and the bottom most layer being mild steel. The Poison's ratio is kept constant along the beam, as Poisson's ratio for most materials lies between $0.35-0.5$, hence varying it would not produce any significant changes but only increase the computational burden. The power law equation which gives the material property at any point of the cross-section for FGM has been given in Eq. (1)

$\mathrm{P}(\mathrm{t})=(\mathrm{P}($ top $)-\mathrm{P}($ bottom $)) *\left(\frac{2 \mathrm{n}+\mathrm{h}}{2 \mathrm{~h}}\right)^{\mathrm{p}}+\mathrm{P}($ bottom $)$

Where;

$\mathrm{P}($ top) is the property of material in top layer.

$\mathrm{P}$ (bottom) is the property of material in bottom layer. $\mathrm{n}$ is the distance of point from the neutral axis, where

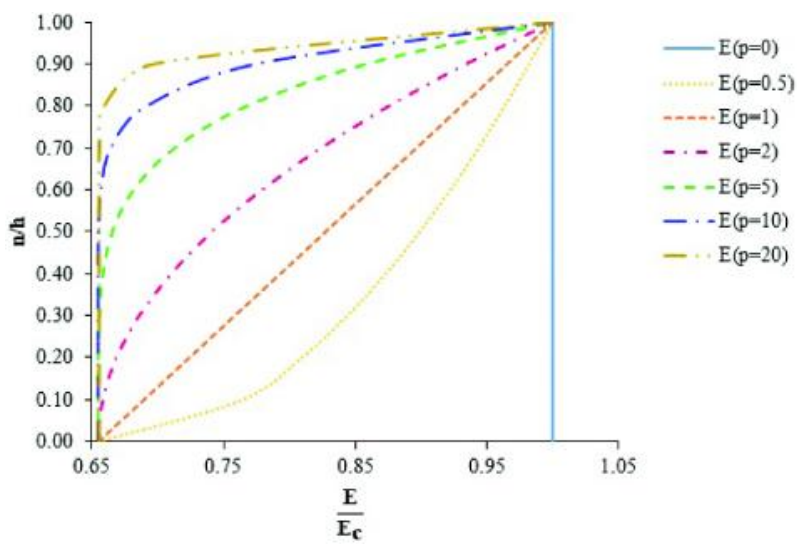

Fig. 3: Shows the variation of young's modulus of a mild steel-alumina FGB along its thickness direction

material properties are to be calculated.

$h$ is the depth of the beam.

$\mathrm{p}$ is the power.

\section{Kinematics}

This paper has adopted twoco-ordinate systems (as shown in Fig. 4.): one is the Cartesian co-ordinate system (x, y, z), second is an orthogonal system (n, s, $z$ ), where ' $s$ ' being contour co-ordinate which varies along the profile of the section with its point of origin ' $O$ ' on the section, ' $n$ ' is in the thickness direction and $\mathrm{z}$ along the longitudinal direction.

The beam model has been adapted from Lee (2005) and has been presented briefly in the subsequent sections. The basic assumptions for the kinematics of thin-walled beams are stated as follows:

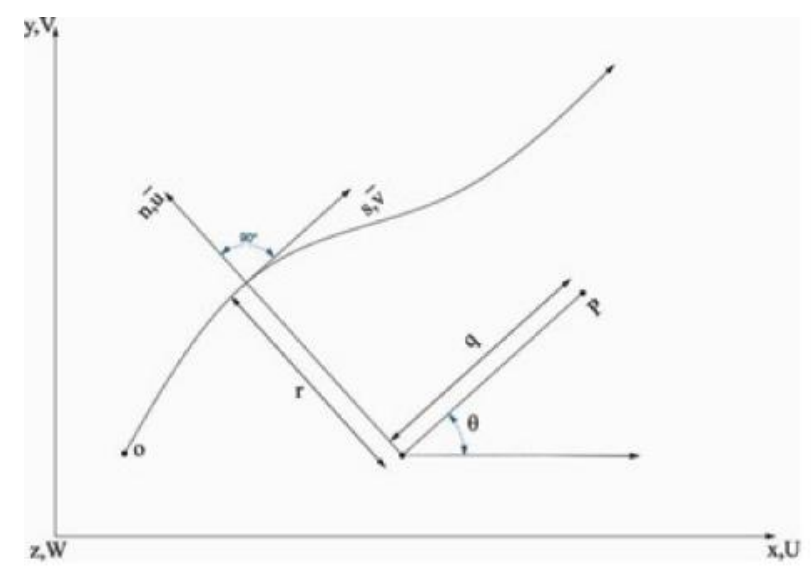

Fig. 4: Co-ordinate system of functionally graded beam 
1. The mid-surface of any thin wall does not deform in its own plane i.e. $\bar{\gamma}_{\mathrm{ns}}=0$.

2. Transverse and warping shear strains are assumed to be uniform throughout the crosssection.

Using the first assumption we can express the mid surface displacements $\bar{u}$ and $\bar{v}$ in terms of pole displacements $\mathrm{U}, \mathrm{V}$ in the $\mathrm{x}, \mathrm{y}$ directions respectively and the pole rotation angle $\Phi$ as;

$$
\begin{aligned}
& \overline{\mathrm{u}}(\mathrm{s}, \mathrm{z})=\mathrm{U}(\mathrm{z}) \sin \theta-\mathrm{V}(\mathrm{z}) \cos \theta-\mathrm{q}(\mathrm{s}) \Phi(\mathrm{z}) \\
& \overline{\mathrm{v}}(\mathrm{s}, \mathrm{z})=\mathrm{U}(\mathrm{z}) \cos \theta+\mathrm{V}(\mathrm{z}) \sin \theta+\mathrm{r}(\mathrm{s}) \Phi(\mathrm{z})
\end{aligned}
$$

The mid surface shear strains can be defined as:

$$
\begin{aligned}
& \bar{\gamma}_{\mathrm{nz}}=\gamma_{\mathrm{xz}}^{0}(\mathrm{z}) \sin \theta-\gamma_{\mathrm{yz}}^{0}(\mathrm{z}) \cos \theta+\mathrm{q}(\mathrm{s}) \gamma_{\omega}^{0}(\mathrm{z}) \\
& \bar{\gamma}_{\mathrm{sz}}=\gamma_{\mathrm{xz}}^{0}(\mathrm{z}) \cos \theta-\gamma_{\mathrm{yz}}^{0}(\mathrm{z}) \sin \theta+\mathrm{r}(\mathrm{s}) \gamma_{\omega}^{0}(\mathrm{z})
\end{aligned}
$$

From continuum mechanics we get;

$$
\begin{aligned}
& \overline{\mathrm{w}}(\mathrm{s}, \mathrm{z})=\mathrm{W}(\mathrm{z})+\mathrm{x} \Psi_{\mathrm{y}}(\mathrm{x})+\mathrm{y}_{\mathrm{x}}(\mathrm{x})+\omega(\mathrm{s}) \Psi_{\omega}(\mathrm{x}) \\
& \Psi_{\mathrm{y}}=\gamma_{\mathrm{xz}}^{\mathrm{o}}-\frac{\mathrm{dU}}{\mathrm{dz}} \\
& \Psi_{\mathrm{x}}=\gamma_{\mathrm{yz}}^{\mathrm{o}}-\frac{\mathrm{dV}}{\mathrm{dz}} \\
& \Psi_{\omega}=\gamma_{\omega}^{\mathrm{o}}-\frac{\mathrm{d} \Phi}{\mathrm{dz}}
\end{aligned}
$$

Where, $\Psi_{\mathrm{y}}, \Psi_{\mathrm{x}}$ and $\Psi_{\omega}$ are the rotation of the cross-section along $x, y$ and $z$ respectively and $\omega(\mathrm{s})$ is called warping function and is defined as;

$$
\omega(\mathrm{s})=\oint_{\Omega} \mathrm{rds}
$$

The displacements of any arbitrary point along the thickness direction are defined as;

$$
\mathrm{u}(\mathrm{n}, \mathrm{s}, \mathrm{z})=\overline{\mathrm{u}}(\mathrm{s}, \mathrm{z})
$$

$$
\begin{aligned}
& \mathrm{v}(\mathrm{n}, \mathrm{s}, \mathrm{z})=\overline{\mathrm{v}}(\mathrm{s}, \mathrm{z})+\mathrm{n} \bar{\psi}_{\mathrm{s}} \\
& \mathrm{w}(\mathrm{n}, \mathrm{s}, \mathrm{z})=\overline{\mathrm{w}}(\mathrm{s}, \mathrm{z})+\mathrm{n} \bar{\psi}_{\mathrm{z}}
\end{aligned}
$$

Where, $\bar{\psi}_{\mathrm{s}}$ and $\bar{\psi}_{\mathrm{z}}$ represent the rotation of the transverse normal about the $s$ and $z$ axis, respectively and $n$ is the distance of the point in consideration from the mid-surface. The transverse normal rotations are defined as;

$$
\begin{aligned}
& \bar{\psi}_{\mathrm{s}}=-\frac{\partial \mathrm{u}}{\partial \mathrm{s}} \\
& \bar{\psi}_{\mathrm{z}}=-\frac{\partial \mathrm{u}}{\partial \mathrm{s}}=\Psi_{\mathrm{y}} \sin \theta-\Psi_{\mathrm{x}} \cos \theta-\mathrm{q} \Psi_{\omega}
\end{aligned}
$$

\section{Strain}

The strain at an arbitrary point in the cross section can be represented as:

$$
\varepsilon_{\mathrm{s}}=\overline{\varepsilon_{\mathrm{s}}}+\mathrm{n} \overline{\mathrm{\kappa}_{\mathrm{s}}}
$$

$$
\varepsilon_{\mathrm{z}}=\bar{\varepsilon}_{\mathrm{z}}+\mathrm{n} \bar{\kappa}_{\mathrm{z}}
$$

$$
\begin{aligned}
& \gamma_{\mathrm{sz}}=\bar{\gamma}_{\mathrm{sz}}+\mathrm{n} \bar{\kappa}_{\mathrm{sz}} \\
& \gamma_{\mathrm{nz}}=\bar{\gamma}_{\mathrm{nz}}+\mathrm{n} \bar{\kappa}_{\mathrm{nz}}
\end{aligned}
$$

Where,

$$
\begin{gathered}
\bar{\varepsilon}_{\mathrm{s}}=\frac{\partial \overline{\mathrm{v}}}{\partial \mathrm{s}} \\
\bar{\varepsilon}_{\mathrm{z}}=\frac{\partial \overline{\mathrm{w}}}{\partial \mathrm{s}}
\end{gathered}
$$

$$
\bar{\kappa}_{\mathrm{s}}=\frac{\partial \overline{\psi_{\mathrm{s}}}}{\partial \mathrm{s}}
$$

$$
\bar{\kappa}_{\mathrm{z}}=\frac{\partial \bar{\psi}_{\mathrm{z}}}{\partial \mathrm{z}}
$$

$$
\bar{\kappa}_{\mathrm{sz}}=\frac{\partial \bar{\psi}_{\mathrm{z}}}{\partial \mathrm{s}}+\frac{\partial \bar{\psi}_{\mathrm{s}}}{\partial \mathrm{z}}
$$




$$
\bar{\kappa}_{\mathrm{nz}}=0
$$

All other strains are identically equal to zero. Now, by substituting Eqs. (2),(3),(4)\&(7) into Eq. (10) we get;

$$
\begin{aligned}
& \overline{\varepsilon_{z}}=\varepsilon_{z}^{0}+x \kappa_{y}+y \kappa_{x}+\omega \kappa_{\omega} \\
& \bar{\kappa}_{z}=\kappa_{y} \sin \theta-\kappa_{x} \cos \theta-q \kappa_{\omega}
\end{aligned}
$$

Where $\kappa_{\mathrm{z}}^{0}, \kappa_{\mathrm{x}}, \kappa_{\mathrm{y}} \cdot \kappa_{\mathrm{sz}}$ and $\kappa_{\omega}$ denote the midsurface axial strain, curvatures in $x$ and $y$, twisting curvature and warping curvature respectively and can be expressed as;

$$
\begin{aligned}
& \varepsilon_{\mathrm{z}}^{0}=\frac{\mathrm{dW}}{\mathrm{dz}} \\
& \kappa_{\mathrm{x}}=\frac{\mathrm{d} \Psi_{\mathrm{x}}}{\mathrm{dz}} \\
& \kappa_{\mathrm{y}}=\frac{\mathrm{d} \Psi_{\mathrm{y}}}{\mathrm{dz}} \\
& \kappa_{\omega}=\frac{\mathrm{d} \Psi_{\omega}}{\mathrm{dz}} \\
& \kappa_{\mathrm{sz}}=\frac{\mathrm{d} \Phi}{\mathrm{dz}}-\Psi_{\omega}
\end{aligned}
$$

\section{Energy Equations}

Strain energy of the beam is given by:

$$
\text { S.E. }=\frac{1}{2} \times \iiint_{\mathrm{V}}\left(\sigma_{\mathrm{z}} \varepsilon_{\mathrm{z}}+\sigma_{\mathrm{sz}} \gamma_{\mathrm{sz}}+\sigma_{\mathrm{nz}} \gamma_{\mathrm{nz}}\right) \mathrm{dV}
$$

The assumption that the $\sigma_{2}=0$ shall be followed in this paper as it produces better results compared to the assumption $\varepsilon_{2}=0$, as inferred by Lee (2005) for laminate composites and Kim et al. (2016) for functionally graded materials.

Substituting Eq. (9) in Eq. (13) and then taking the variation of the equation so obtained, we get;

$$
\begin{aligned}
\delta \text { S.E. }= & \frac{1}{2} \mathrm{x} \int_{0}^{\mathrm{L}}\left(\mathrm{N}_{\mathrm{z}} \delta \varepsilon_{\mathrm{z}}^{0}+\mathrm{M}_{\mathrm{y}} \delta \kappa_{\mathrm{y}}\right. \\
& +\mathrm{M}_{\mathrm{x}} \delta \kappa_{\mathrm{x}}+\mathrm{M}_{\omega} \delta \kappa_{\omega}+\mathrm{M}_{\mathrm{y}} \delta \kappa_{\mathrm{y}} \\
& +\mathrm{M}_{\mathrm{t}} \delta \kappa_{\mathrm{sz}}+\mathrm{V}_{\mathrm{x}} \delta \gamma_{\mathrm{xz}}^{0}+\mathrm{V}_{\mathrm{y}} \delta \gamma_{\mathrm{yz}}^{0} \\
& \left.+\mathrm{T} \delta \gamma_{\omega}^{0}\right) \mathrm{dz}
\end{aligned}
$$

Where, $L$ is the length of the beam and $N_{z}, V_{x}$, $V_{y}, M_{x}, M_{y}, M_{\omega}$, and $T$ are the axial force, shear force in $x$ and $y$ direction, bending moments in the $x$ - and $y$ directions, warping moment, torsional moment and warp torsion respectively and are defined as follows

$$
\begin{aligned}
& \mathrm{N}_{\mathrm{z}}=\int_{\mathrm{A}} \sigma_{\mathrm{z}} \mathrm{dA} \\
& \mathrm{M}_{\mathrm{y}}=\int_{\mathrm{A}} \sigma_{\mathrm{z}}(\mathrm{x}+\mathrm{n} \sin \theta) \mathrm{dA} \\
& \mathrm{M}_{\mathrm{x}}=\int_{\mathrm{A}} \sigma_{\mathrm{z}}(\mathrm{y}-\mathrm{n} \cos \theta) \mathrm{dA} \\
& \mathrm{M}_{\omega}=\int_{\mathrm{A}} \sigma_{\mathrm{z}}(\omega-\mathrm{nq}) \mathrm{dA} \\
& \mathrm{M}_{\mathrm{t}}=\int_{\mathrm{A}} \mathrm{n} \sigma_{\mathrm{sz}} \mathrm{dA} \\
& \mathrm{V}_{\mathrm{x}}=\int_{\mathrm{A}}\left(\sigma_{\mathrm{sz}} \cos \theta+\sigma_{\mathrm{nz}} \sin \theta\right) \mathrm{dA} \\
& \mathrm{V}_{\mathrm{y}}=\int_{\mathrm{A}}\left(\sigma_{\mathrm{sz}} \sin \theta-\sigma_{\mathrm{nz}} \cos \theta\right) \mathrm{dA} \\
& \mathrm{T}=\int_{\mathrm{A}}\left(\mathrm{r} \sigma_{\mathrm{sz}}-\mathrm{q} \sigma_{\mathrm{nz}}\right) \mathrm{dA}
\end{aligned}
$$

Principle of minimum potential energy states that $\delta \Pi=0$, where $\Pi=$ S.E. + Work done by external forces $\left(\mathrm{W}_{\text {external }}\right)$, therefore;

$$
\begin{aligned}
& \frac{1}{2} \times \int_{0}^{\mathrm{L}}\left(\mathrm{N}_{\mathrm{z}} \delta \varepsilon_{\mathrm{z}}^{0}+\mathrm{M}_{\mathrm{y}} \delta \kappa_{\mathrm{y}}\right. \\
& \quad+\mathrm{M}_{\mathrm{x}} \delta \kappa_{\mathrm{x}}+\mathrm{M}_{\omega} \delta \kappa_{\omega}+\mathrm{M}_{\mathrm{y}} \delta \kappa_{\mathrm{y}}
\end{aligned}
$$




$$
\begin{aligned}
& +\mathrm{M}_{\mathrm{t}} \delta \kappa_{\mathrm{sz}}+\mathrm{V}_{\mathrm{x}} \delta \gamma_{\mathrm{xz}}^{0}+\mathrm{V}_{\mathrm{y}} \delta \gamma_{\mathrm{yz}}^{0} \\
& +\left(\mathrm{T} \delta \gamma_{\omega}^{0}\right) \mathrm{dz}+\delta \mathrm{W}_{\text {external }}=0
\end{aligned}
$$

\section{Constitutive Equation}

The in-plane stress-strain relation for the FG beam is given as follows:

$$
\left\{\begin{array}{c}
\sigma_{\mathrm{z}} \\
\sigma_{\mathrm{sz}}
\end{array}\right\}=\left[\begin{array}{cc}
\mathrm{E}(\mathrm{n}) & 0 \\
0 & \mathrm{G}(\mathrm{n})
\end{array}\right] \times\left\{\begin{array}{c}
\varepsilon_{\mathrm{z}} \\
\gamma_{\mathrm{sz}}
\end{array}\right\}
$$

The out of plane stress is given by,

$$
\sigma_{\mathrm{nz}}=\mathrm{G}(\mathrm{n}) \mathrm{x} \gamma_{\mathrm{nz}}
$$

The Poisson's ratio is kept constant through the depth of the beam as for ceramics and metals the Poisson's ratio is in the range $0.28-0.32$, and hence it variation along the depth would hardly differ but will only add to the computational burden.

$$
\left[\begin{array}{lll}
A_{i j} & B_{i j} & D_{i j}
\end{array}\right]=\int \bar{Q}_{i j}\left[\begin{array}{lll}
1 & n & n^{2}
\end{array}\right] d n
$$

where $\mathrm{A}_{\mathrm{ij}}, \mathrm{B}_{\mathrm{ij}}$, and $\mathrm{D}_{\mathrm{ij}}$ denote the extension, coupling and bending stiffness's, respectively.

This paper has considered the material distribution as shown in Fig. 5.

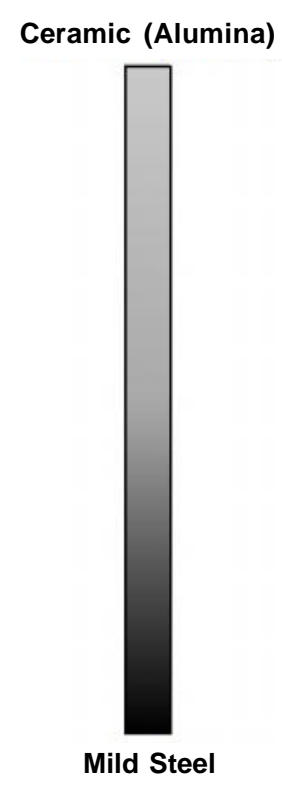

Fig. 5: Material distribution along the thickness
The explicit expressions for $\mathrm{A}_{\mathrm{ij}}, \mathrm{B}_{\mathrm{ij}}$, and $\mathrm{D}_{\mathrm{ij}}$ are;

$$
\mathrm{A}_{11}=\left(\mathrm{E}_{\text {ceramic }}+\mathrm{pE} \mathrm{E}_{\text {metal }}\right)\left(\frac{\mathrm{h}}{\mathrm{p}+1}\right)
$$

$$
\mathrm{B}_{11}=\left(\frac{1}{p+2}-\frac{1}{2(\mathrm{p}+1)}\right)\left(\mathrm{E}_{\text {ceramic }}-\mathrm{E}_{\text {metal }}\right) \mathrm{h}^{2}
$$

$$
\mathrm{D}_{11}=\left(\frac{\mathrm{E}_{\text {metal }} \mathrm{h}^{3}}{12}\right)+\left(\frac{1}{4(\mathrm{p}+1)}-\frac{1}{\mathrm{p}+2}+\frac{1}{\mathrm{p}+3}\right)
$$

$$
\left(E_{\text {ceramic }}-E_{\text {metal }}\right) h^{3}
$$

$$
\left[\begin{array}{lll}
\mathrm{A}_{66} & \mathrm{~B}_{66} & \mathrm{D}_{66}
\end{array}\right]=\frac{1}{1+v} \times\left[\begin{array}{lll}
\mathrm{A}_{11} & \mathrm{~B}_{11} & \mathrm{D}_{11}
\end{array}\right]
$$

Where; $h$ denotes the thickness of the beam and $p$ is the power of gradation.

\section{Governing Equations}

Consider a transverse uniformly distributed load $q$ acting along $y$ direction on the beams, then the work done by this external load is expressed as,

$$
\delta \mathrm{W}_{\text {external }}=-\int_{0}^{\mathrm{L}} \mathrm{q} \delta \mathrm{Vdz}
$$

The corresponding governing equations obtained from the weak form are,

$$
\begin{aligned}
& \frac{\mathrm{dN}_{\mathrm{z}}}{\mathrm{dz}}=0 \\
& \frac{\mathrm{dV}_{\mathrm{x}}}{\mathrm{dz}}=0 \\
& \frac{\mathrm{dV}_{\mathrm{y}}}{\mathrm{dz}}=\mathrm{q} \\
& \frac{\mathrm{d}\left(\mathrm{M}_{\mathrm{t}}+\mathrm{T}\right)}{\mathrm{dz}}=0
\end{aligned}
$$




$$
\begin{aligned}
\frac{\mathrm{dM}_{\mathrm{x}}}{\mathrm{dz}} & =\mathrm{V}_{\mathrm{y}} \\
\frac{\mathrm{dM}_{\mathrm{y}}}{\mathrm{dz}} & =\mathrm{V}_{\mathrm{x}} \\
\frac{\mathrm{dM}_{\omega}}{\mathrm{dz}} & =\mathrm{T}-\mathrm{M}_{\mathrm{t}}
\end{aligned}
$$

Substituting Eqs. (15) and (17) in Eqs, (22) and then rearranging and uncoupling the degrees of freedom, we get,

$$
\begin{aligned}
& E_{11} \frac{d^{2} W}{d z^{2}}=0 \\
& E_{66}\left(\frac{d^{2} U}{d z^{2}}+\frac{d \Psi_{y}}{d z}\right)=0 \\
& E_{77}\left(\frac{d^{2} V}{d z^{2}}+\frac{d \Psi_{x}}{d z}\right)=q \\
& E_{22} \frac{d^{2} \Phi}{d z^{2}}-\left(E_{55}-E_{88}\right) \frac{d \Psi_{\omega}}{d z}=0 \\
& E_{22} \frac{d^{2} \Psi_{y}}{d z^{2}}-E_{66}\left(\frac{d U}{d x}+\Psi_{y}\right)=0 \\
& E_{44} \frac{d^{2} \Psi z^{2}}{E_{33}} \frac{d^{2} \Psi_{X}}{d z^{2}}-E_{77}\left(\frac{d V}{d x}+\Psi_{x}\right)=0 \\
& \left.E_{58}\right) \frac{d \Phi}{d z}-\left(E_{55}+E_{88}\right) \Psi_{\omega}=0
\end{aligned}
$$

For beam in flexure the Eqs. (23c) \& (23e) shall be used. By careful inspection, it can be seen that these equations are the Timoshenko beam equations (Haque, 2016).

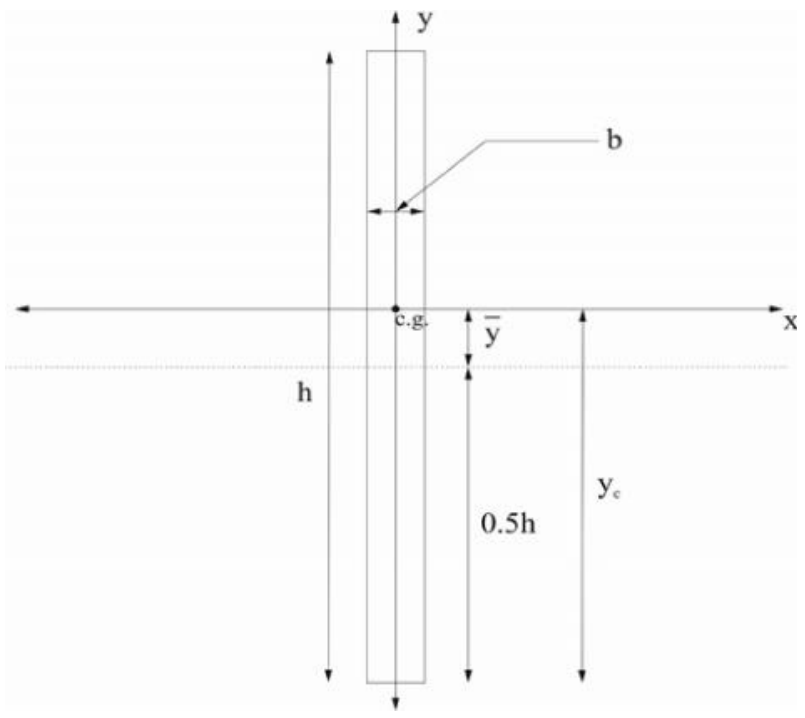

Fig. 6: Cross-sectional view

The individual expressions for thin walled beam as shown in Fig. 6 are as follows,

$$
\begin{aligned}
& \mathrm{E}_{11}=\mathrm{A}_{11} \mathrm{~b} \\
& \mathrm{E}_{22}=\frac{\mathrm{A}_{11} \mathrm{~b}^{3}}{12} \\
& \mathrm{E}_{33}=\left(\mathrm{A}_{11} \overline{\mathrm{y}}^{2}-2 \mathrm{~B}_{11} \overline{\mathrm{y}}+\mathrm{D}_{11}\right) \mathrm{b} \\
& \mathrm{E}_{44}=\frac{\left(\mathrm{A}_{11} \overline{\mathrm{y}}^{2}-2 \mathrm{~B}_{11} \overline{\mathrm{y}}+\mathrm{D}_{11}\right) \mathrm{b}^{3}}{12} \\
& \mathrm{E}_{55}=\mathrm{D}_{66} \mathrm{~b} \\
& \mathrm{E}_{77}=\mathrm{E}_{66}=\mathrm{A}_{66} \mathrm{~b} \\
& \mathrm{E}_{88}=\mathrm{A}_{66} \mathrm{~b} \overline{\mathrm{y}}^{2}+\frac{\mathrm{A}_{66} \mathrm{~b}^{3}}{12}
\end{aligned}
$$

Where, $\bar{y}$ denotes the distance of the neutral axis from the half depth axis and is given by;

$$
\bar{y}=\left|y_{c}-\frac{h}{2}\right|
$$




$$
\mathrm{y}_{\mathrm{c}}=\frac{\mathrm{h}}{2}-\frac{\mathrm{B}_{11}}{\mathrm{~A}_{11}}
$$

\section{Methodology}

In order to calculate the analytical results based on the system of differential equations (Eqs. 23a through 23g), a MATLAB code was prepared which can formulate the results based on user defined material and geometric characteristics for different loading and boundary conditions. The logical flow of the code has been presented in the form of a flowchart as shown in Fig. 7.

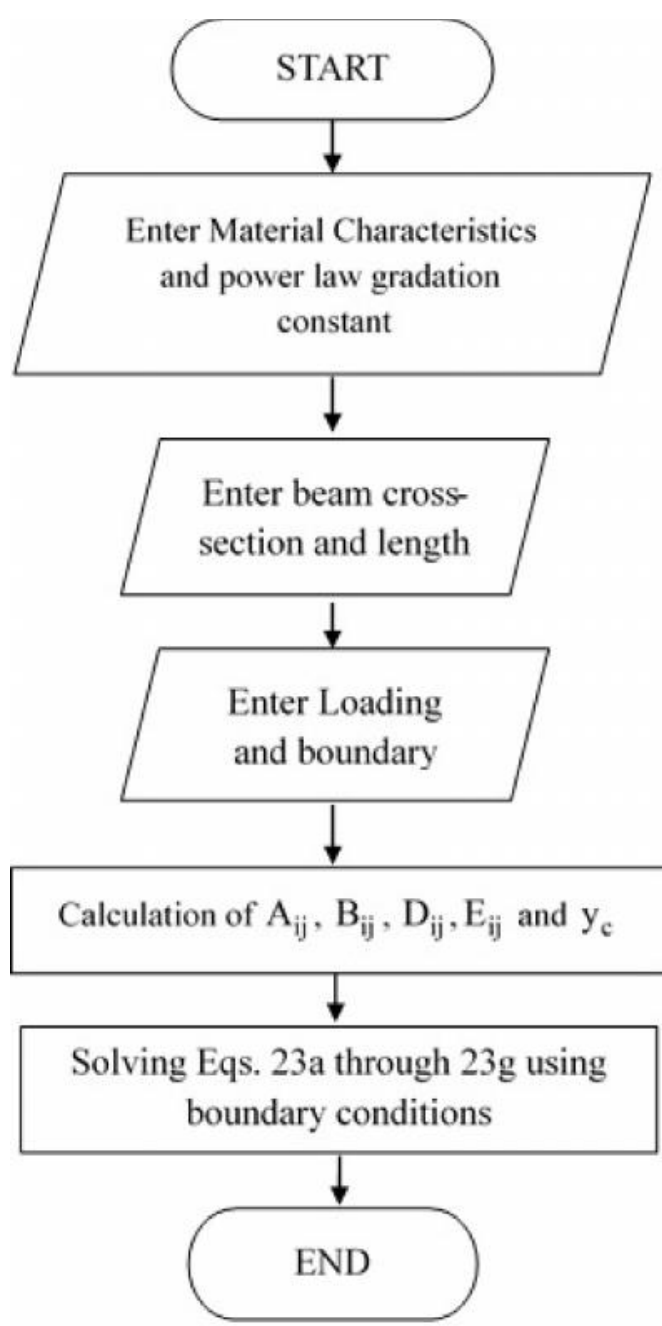

Fig. 7: Flow chart of analytical model

\section{Results and Discussion}

In the numerical model, a thin functionally graded rectangular section has been considered to investigate the effects of power law on the flexure response of the beam considering first order shear deformation. A thin rectangular section has been taken so as to mimic the response of a web in I section. As we know from previous studies that in pure flexure the major load is taken by the web for I section through shear and the flanges contribute very less in the response. So, for a preliminary check as tohow accurate the model is, this study has been conducted. The beam in consideration is of length $\mathrm{L}=1.5 \mathrm{~m}$, depth $\mathrm{h}=0.1 \mathrm{~m}$ and width $b=0.005 \mathrm{~m}$, and materials varied in the thickness direction are alumina $\left(\mathrm{E}_{\mathrm{c}}=320.7 \mathrm{GPa}\right)$ and mild steel $\left(\mathrm{E}_{\mathrm{m}}=210.7 \mathrm{GPa}\right)$. The cross-section of the beam is as shown in Fig. 6. The variation of depth of neutral

$p$ has been shown in Fig. 8. For $p=0$ the depth of neutral axis is at mid-depth of the beam, as for $p=0$ the material will be purely alumina (as inferred from Eq. 1). As $p$ tends to infinity the depth of neutral axis again tends to mid-surface depth because as $p$ tends to infinity the material tends to behave purely as mild steel,

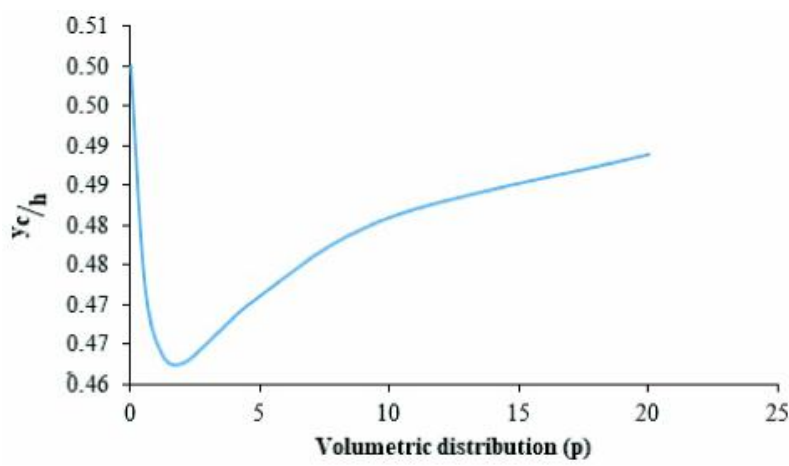

Fig. 8: Variation of depth of neutral axis with volumetric distribution

The response of beam under (a) fixed (cantilever) condition and (b) simply-supported conditionis discussed in the subsequent sections. To get the response of the beam, a MATLAB code has been written and to simulate the response of FGB on ABAQUS (ABAQUS/Standard User's Manual, 2010) the user subroutine UMAT has been incorporated.

\section{Cantilever Boundary}

A uniformly distributed load $\mathrm{q}(\mathrm{qL}=100 \mathrm{kN} / \mathrm{m})$ is applied and boundary conditions are $\mathrm{U}(\mathrm{z}=0)=0, \mathrm{~V}(\mathrm{z}=0)=$ $0, \mathrm{U}(\mathrm{z}=0)=0, \Psi_{\mathrm{x}}(\mathrm{z}=0)=0, \Psi_{\mathrm{y}}(\mathrm{z}=0)=0, \Psi_{\omega}(\mathrm{z}=0)$ 


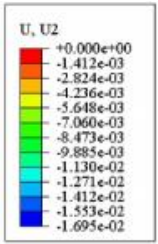

${ }_{2}$
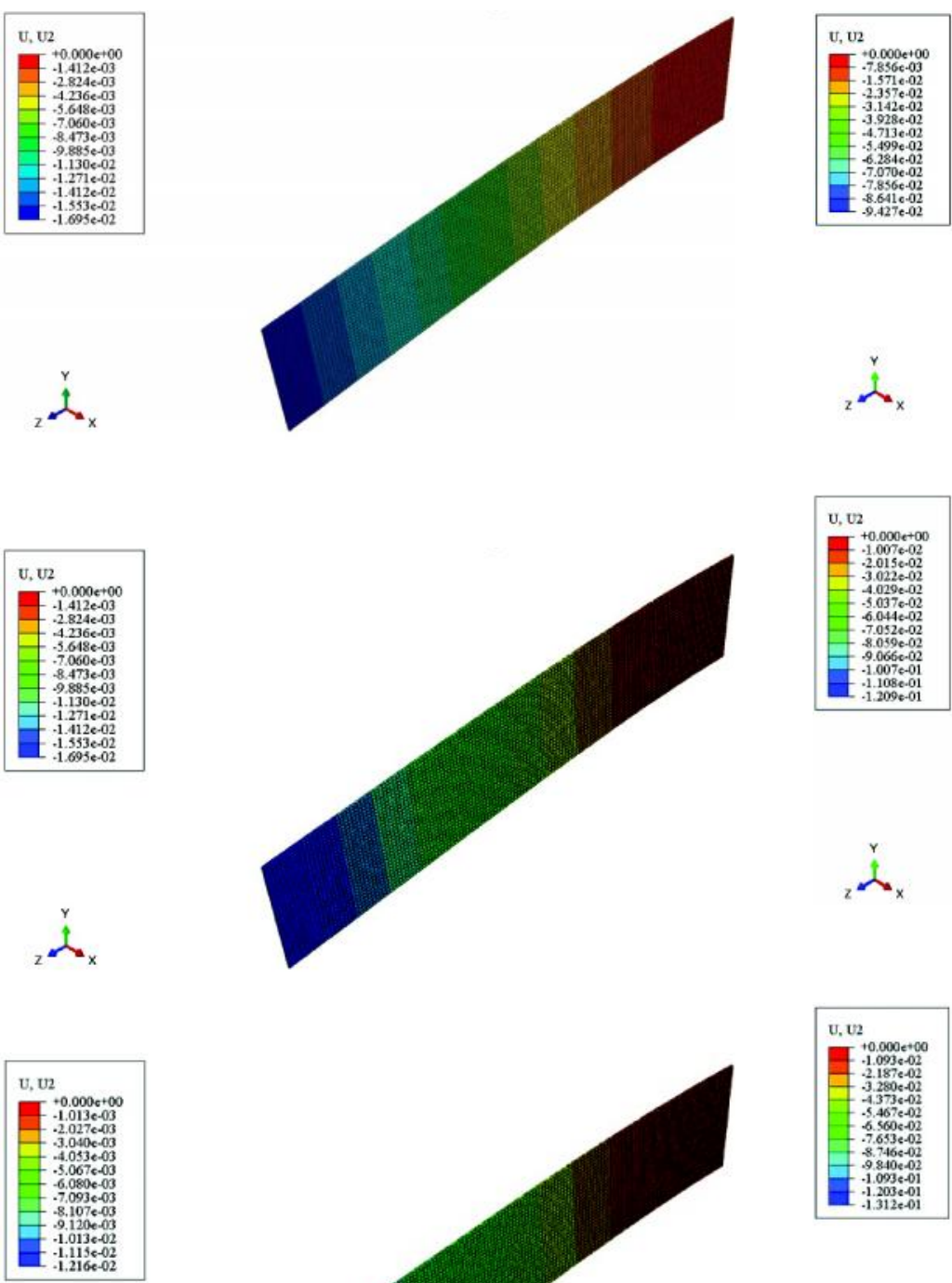

${ }_{2}$
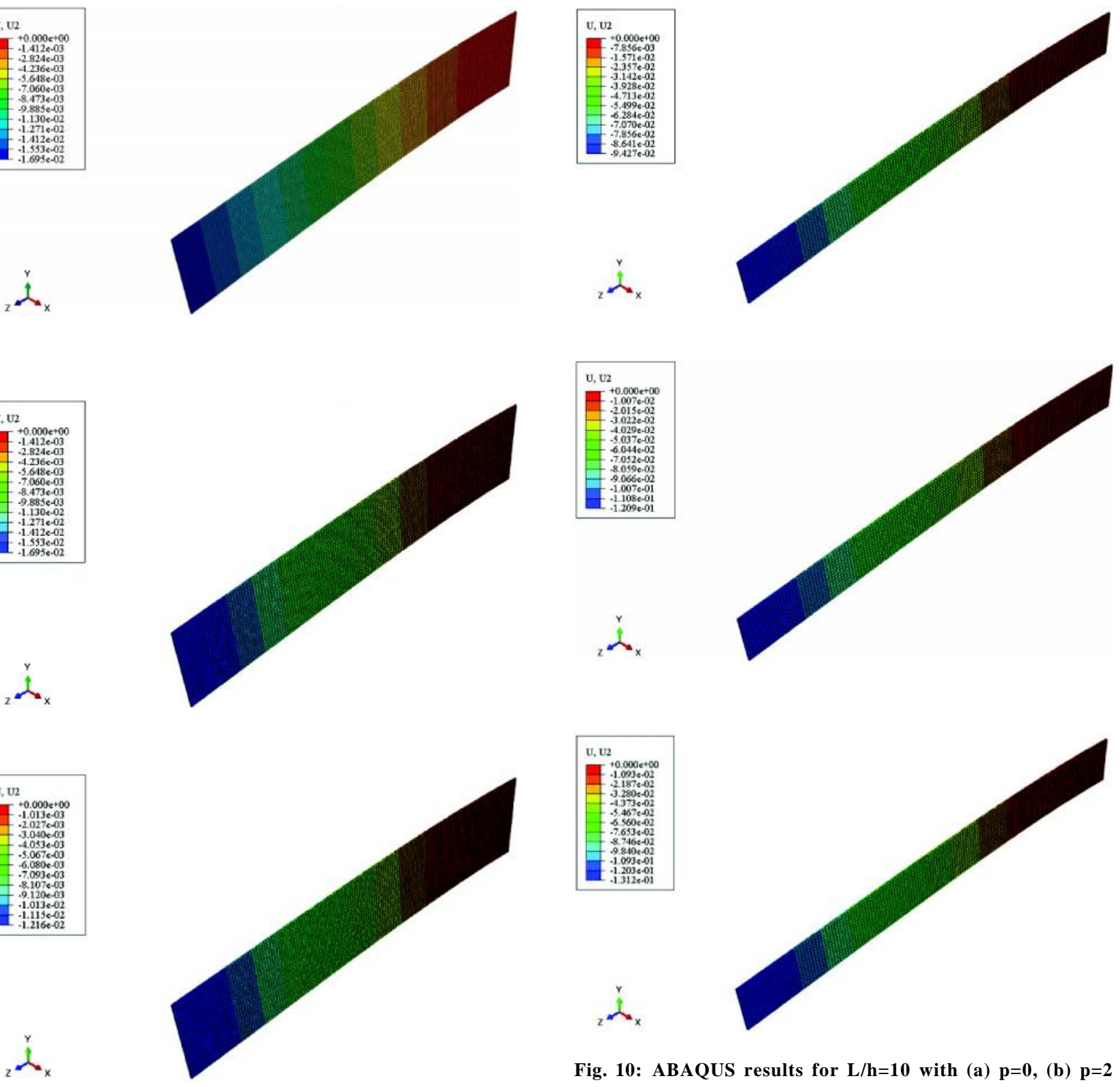

Fig. 10: ABAQUS results for $\mathrm{L} / \mathrm{h}=10$ with (a) $\mathrm{p}=\mathbf{0}$, (b) $\mathrm{p}=\mathbf{2}$ and (c) $p=10$ (by varying depth of the beam)
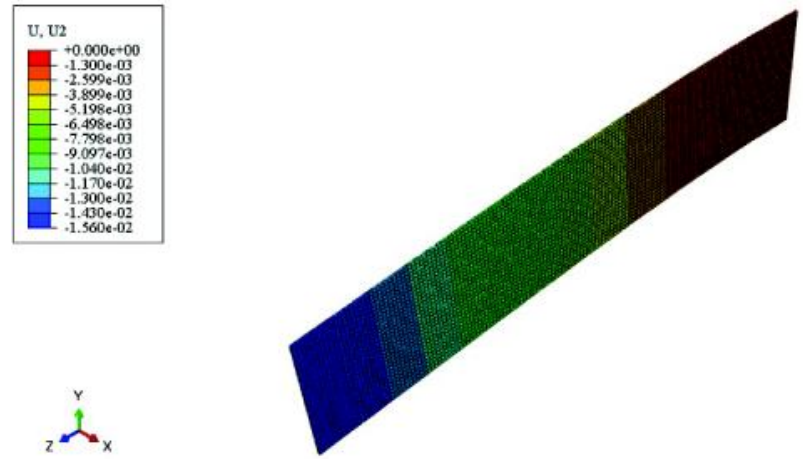

$=0$ and $\Phi(\mathrm{z}=0)=0$. The closed form solution for maximum deflection of a cantilever beam under uniformly distributed load is;

$$
\mathrm{v}_{\max }=\frac{\mathrm{qL}^{4}}{8 \mathrm{E}_{33}}+\frac{\mathrm{qL}^{2}}{2 \mathrm{E}_{77}}
$$

The results obtained have been normalized and plotted in Figs. 14 and 15. The results obtained from analytical model (AN) and ABAQUS (AB) are in good agreement. Comparing Figs. 14 and 15, we see 

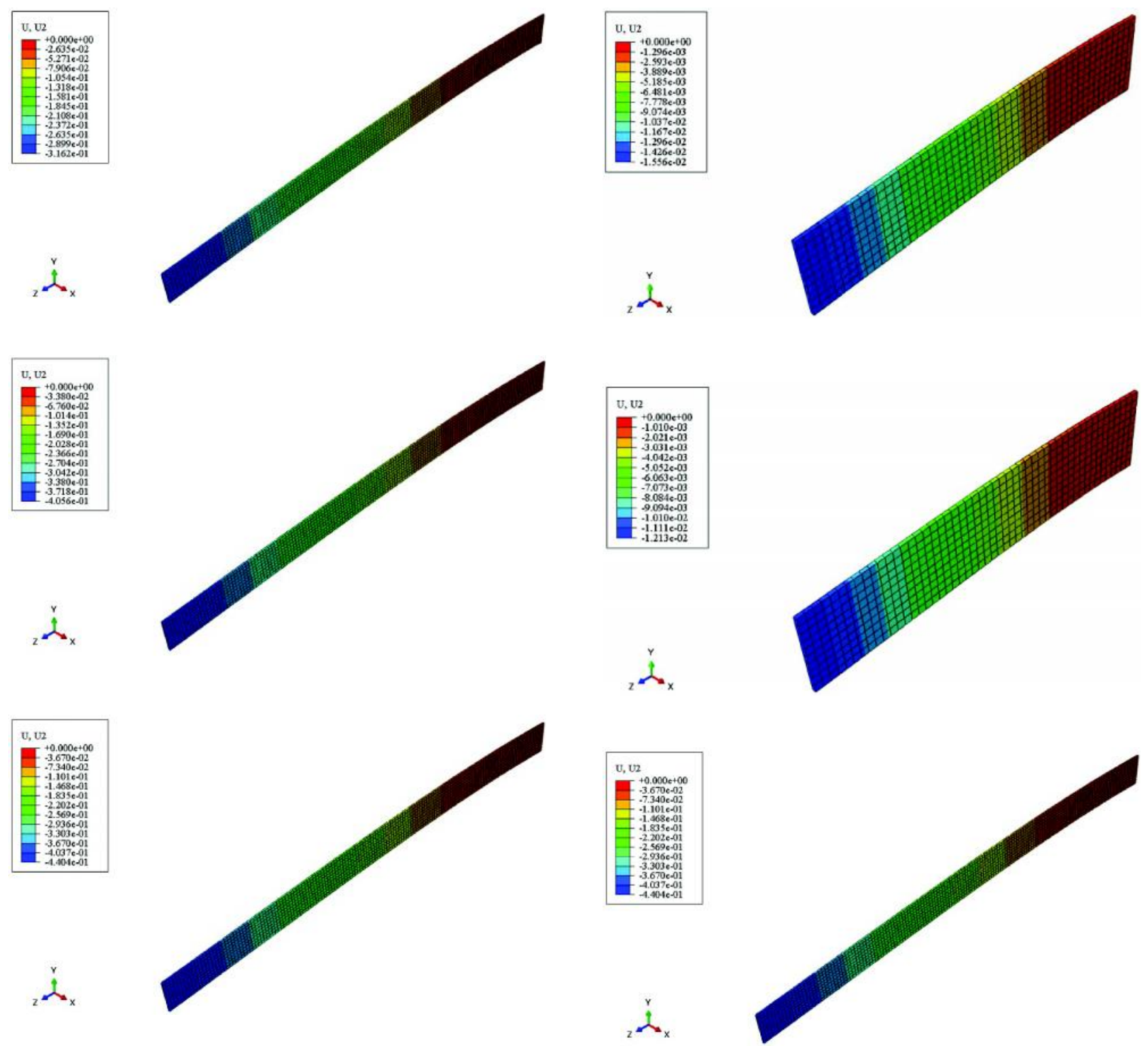

Fig. 11: ABAQUS results for $L / h=15$ with (a) $p=0$, (b) $p=2$ and (c) $p=10$ (by varying depth of the beam)

Fig. 12: ABAQUS results for $L / h=5$ with (a) $p=0$, (b) $p=2$ and (c) $p=10$ (by varying length of the beam)

that even though the material properties vary along the depth, the trends of maximum deflection are hardly affected by changing the length or changing the depth for changing the $\mathrm{L} / \mathrm{h}$ ratio in the parametric study. But the trends are affected as the $\mathrm{L} / \mathrm{h}$ ratio decreases. This is due to influence of shear deformation. The shift of plots from $\mathrm{L} / \mathrm{h}=10$ to $\mathrm{L} / \mathrm{h}=5$ indicates that as the span to depth ratio decreases, the influence of shear deformation increases.

\section{Simply Supported}

A uniformly distributed load $\mathrm{q}(\mathrm{qL}=100 \mathrm{kN} / \mathrm{m})$ is applied and the boundary conditions used are $\mathrm{U}(\mathrm{z}=$ $0)=0, V(z=0)=0, V(z=0)=0, U(z=0)=0, U(z=$ $\mathrm{L})=0, \mathrm{~V}(\mathrm{z}=\mathrm{L})=0, \mathrm{M}_{\mathrm{y}}(\mathrm{z}=0)=0$ and $\mathrm{M}_{\mathrm{y}}(\mathrm{z}=\mathrm{L})=$ 0 . The closed form solution for maximum deflection of a simply supported beam under uniformly distributed load is;

$$
\mathrm{v}_{\max }=\frac{5 \mathrm{qL}^{4}}{384 \mathrm{E}_{33}}+\frac{\mathrm{qL}^{2}}{8 \mathrm{E}_{77}}
$$

As done previously for cantilever beams, the 


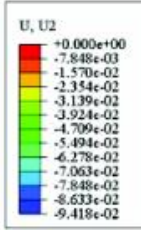

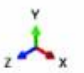
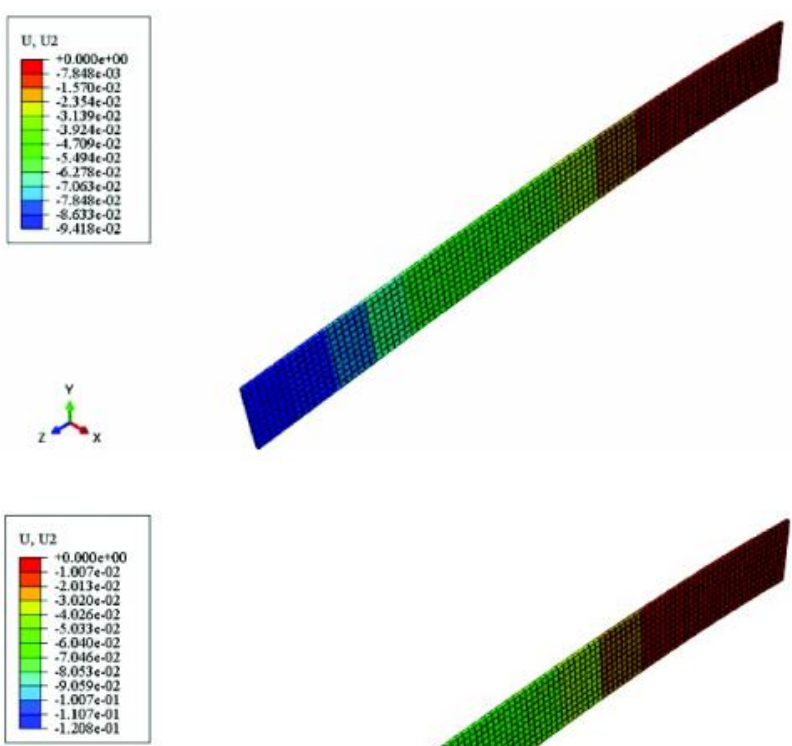

${ }_{z}$
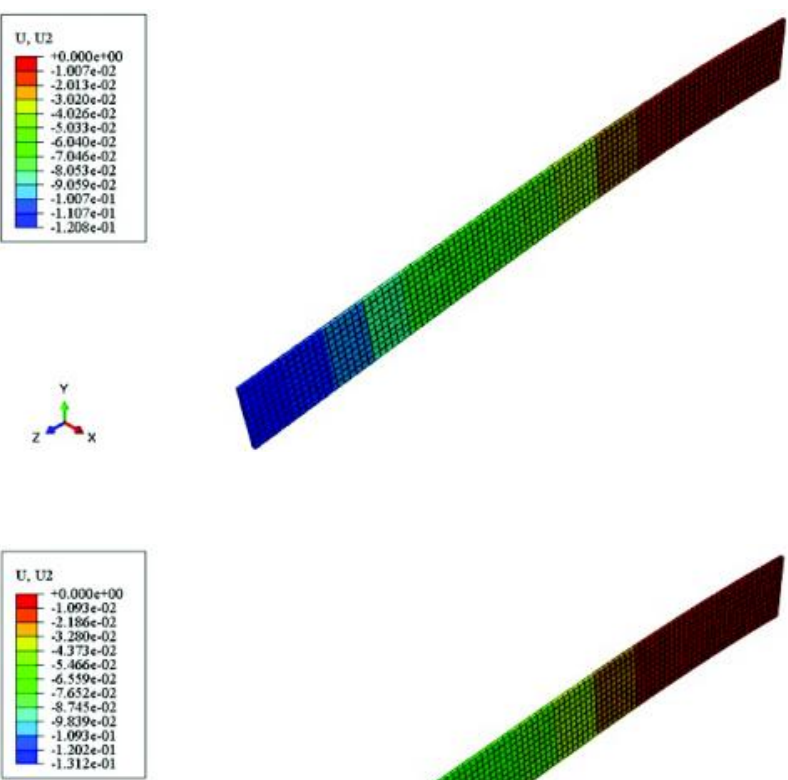

${ }_{2}$

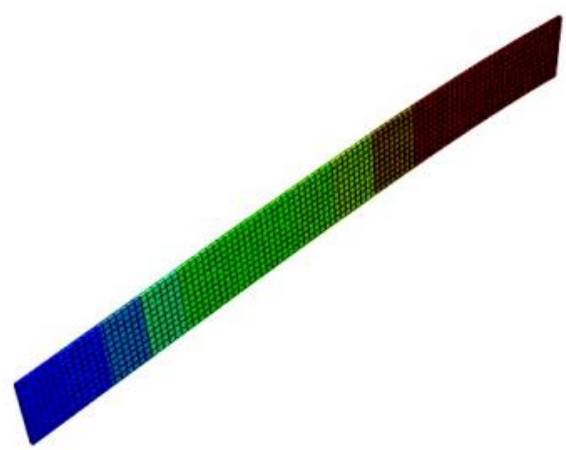

Fig. 13: ABAQUS results for $L / h=10$ with (a) $p=0$, (b) $p=2$ and (c) $p=10$ (by varying length of the beam)

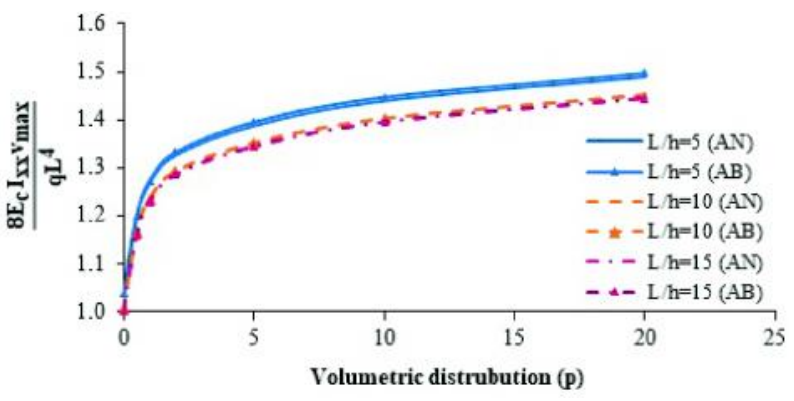

Fig. 14: Normalized maximum deflection $v s$ p (by varying depth of the beam)

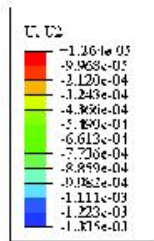

$r$

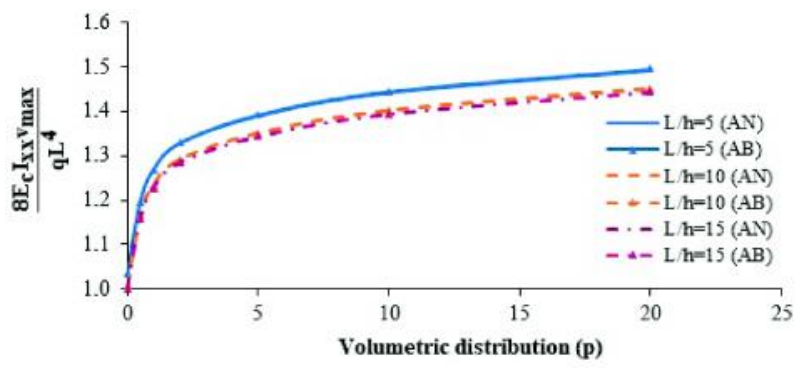

Fig. 15: Normalized maximum deflection $v s$ p (by varying length of the beam)
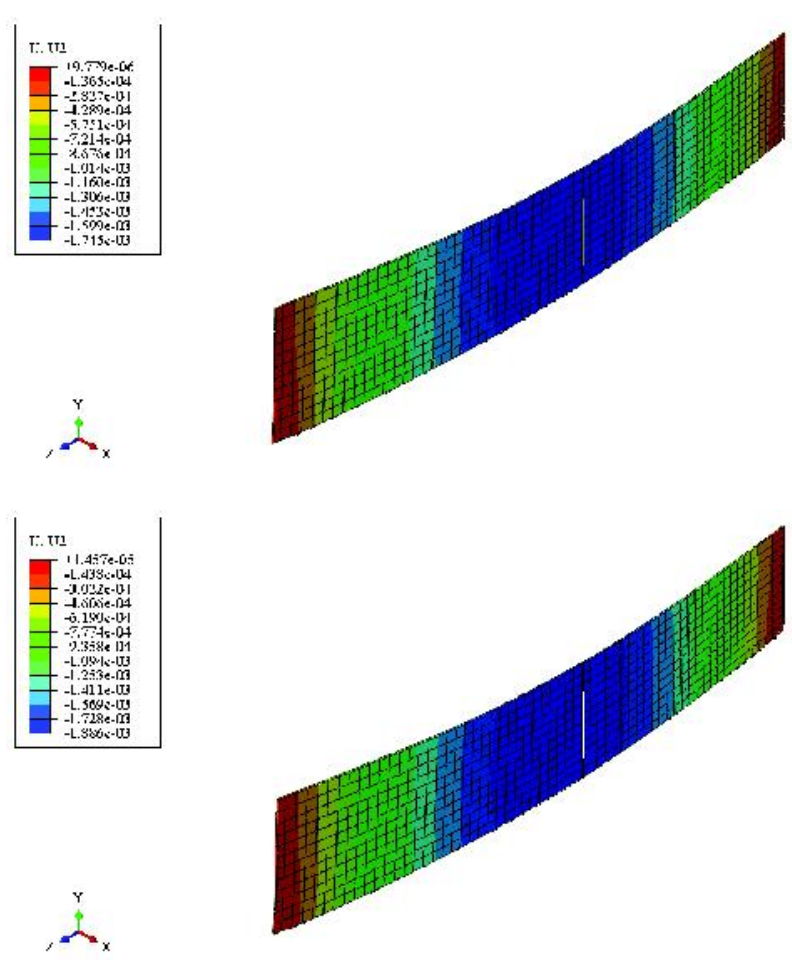

Fig. 16: ABAQUS results for $\mathrm{L} / \mathrm{h}=5$ with (a) $\mathrm{p}=0$, (b) $\mathrm{p}=\mathbf{2}$ and (c) $p=10$ (by varying depth of the beam) 


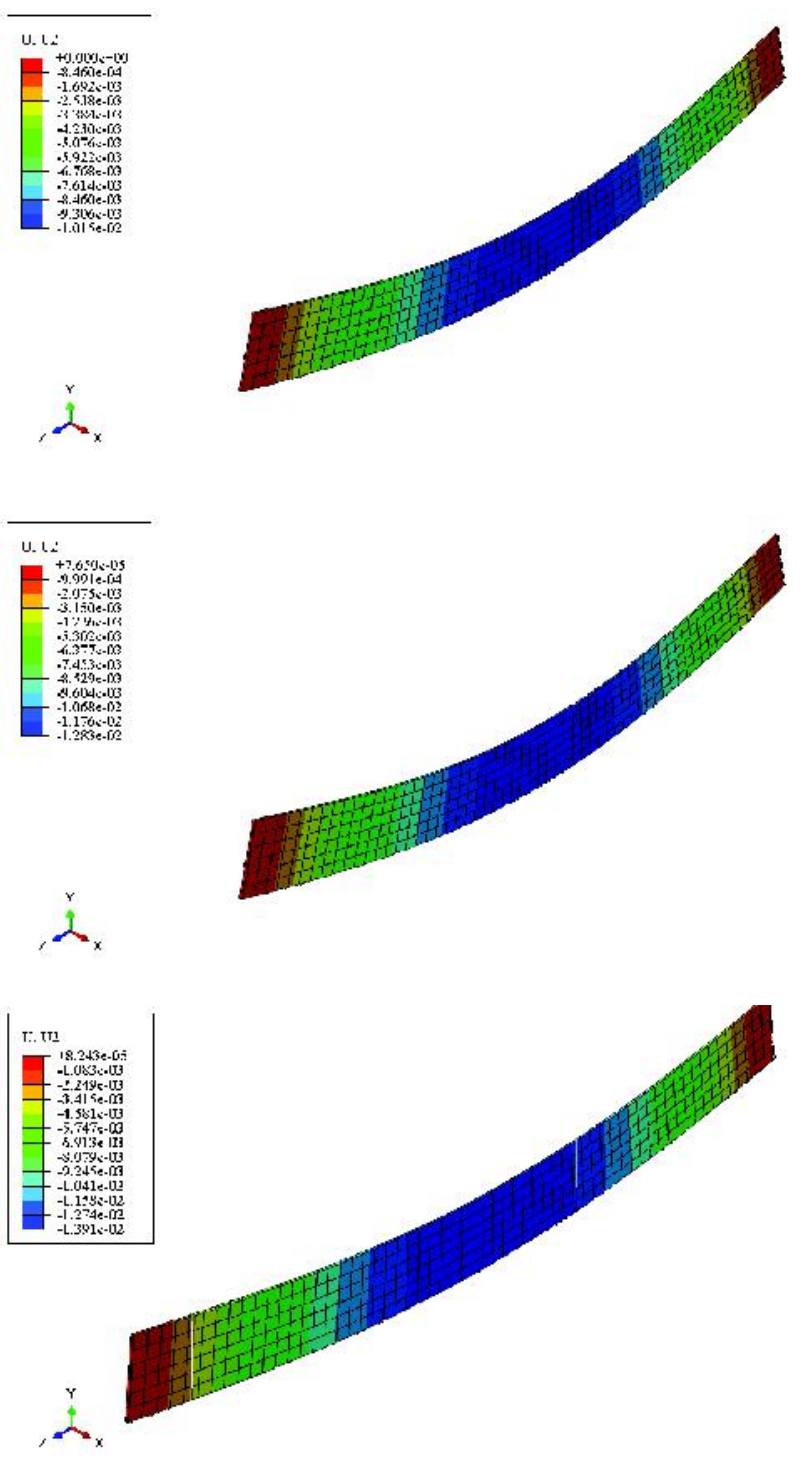

Fig. 17: ABAQUS results for $L / h=10$ with (a) $p=0$, (b) $p=2$ and (c) $p=10$ (by varying depth of the beam)

maximum deflection of the simply supported beam from the analytical model (AN) and ABAQUS (AB) have been normalized and presented in Figs. 21 and 22. As observed in cantilever beams, for simply supported conditions also the trends of maximum deflection are hardly affected by varying length or varying depth (keeping $\mathrm{L} / \mathrm{h}$ constant) in the parametric study, but are affected by changing the $\mathrm{L} / \mathrm{h}$ ratio. This is due to the influence of shear deformation. As the $\mathrm{L} / \mathrm{h}$ ratio decreases this effect increases. From the Figs. 14, 15, 21 and 22, we can also see that as $p$ tends to infinity the maximum deflection value tends to a value that represents the deflection of a purely mild steel beam.
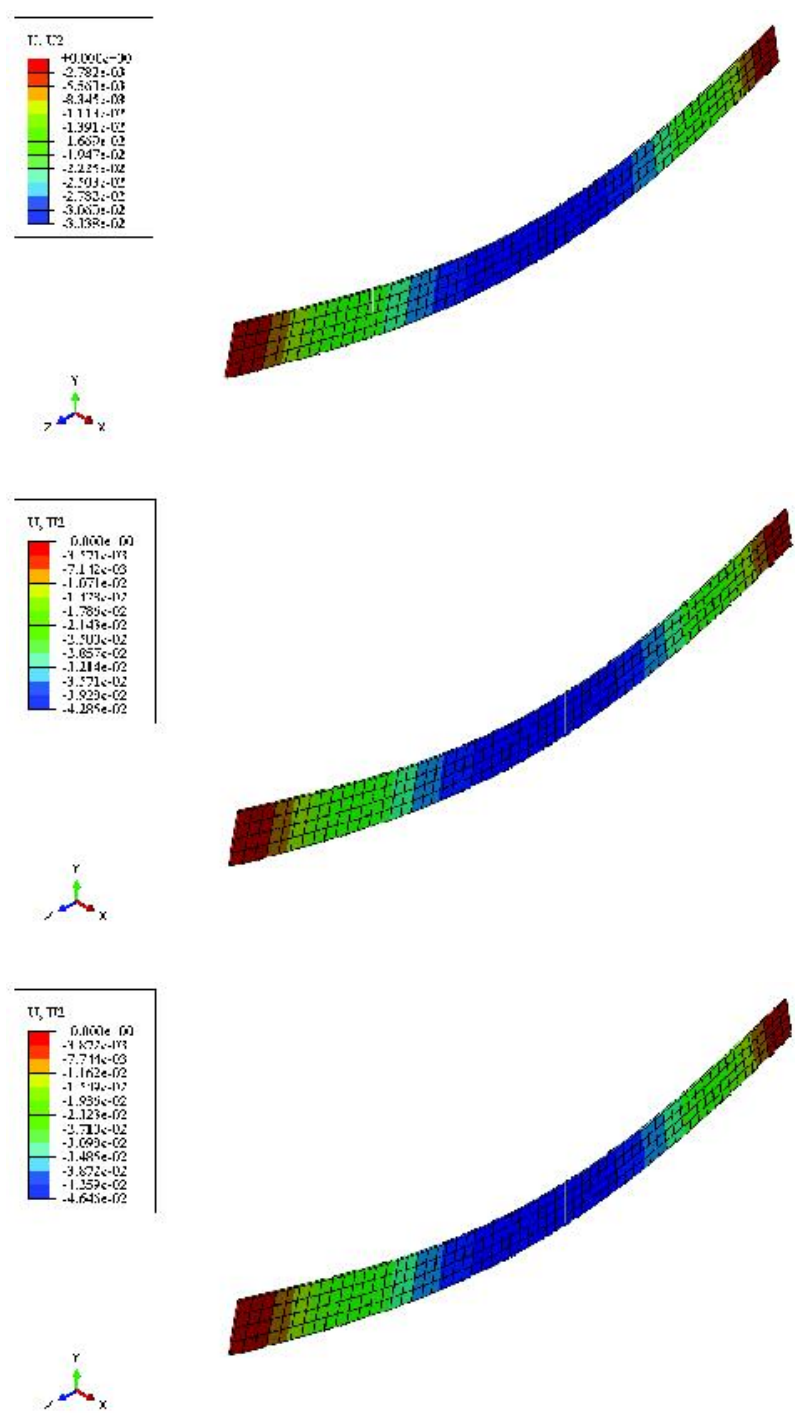

Fig. 18: ABAQUS results for $L / h=15$ with (a) $p=0$, (b) $p=2$ and (c) $p=10$ (by varying depth of the beam)

\section{Conclusions}

An analytical model was developed on MATLAB which can incorporate the governing equations of first order shear deformable thin walled beams whose material varies along the depth direction. The model developed is capable of producing accurate deflection for various boundary conditions, loadings and volumetric distributions (p). The model was formulated using the assumption that the normal stress in the contour direction is zero. The shear effects on functionally graded beam become significant as the span to depth ratio decreases. For validation of results obtained an ABAQUS/CAE simulation was 

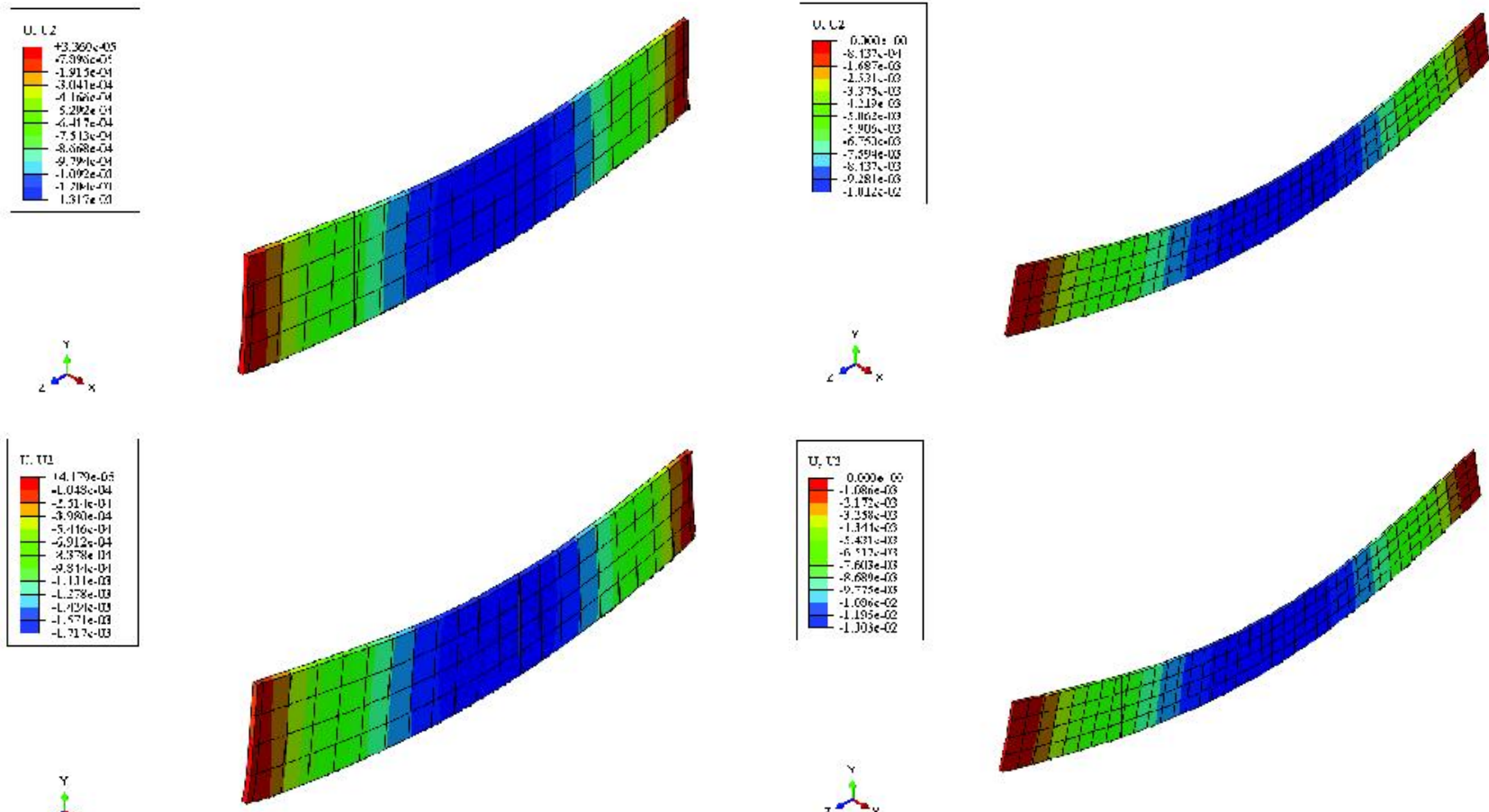

$\stackrel{x}{\infty}$
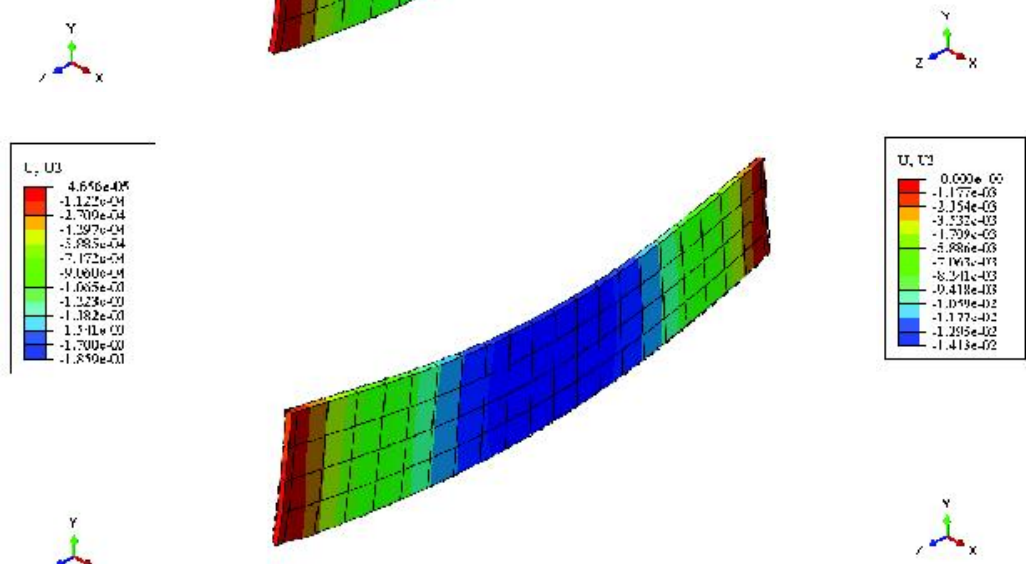

$\stackrel{r}{i}$
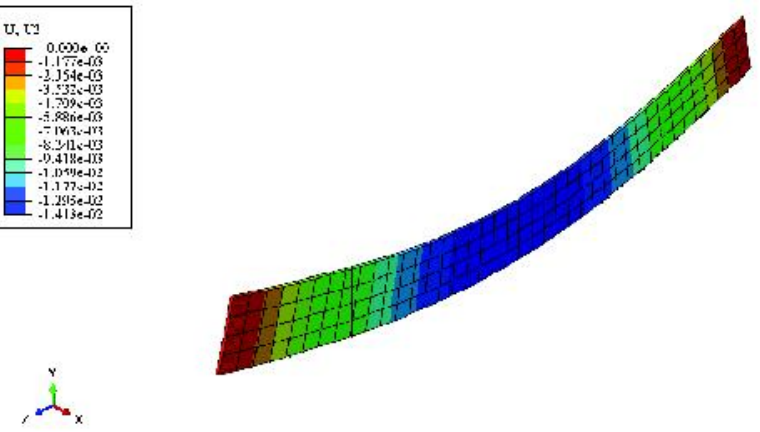

Fig. 19: ABAQUS results for $L / h=5$ with (a) $p=0$, (b) $p=2$ and (c) $\mathrm{p}=10$ (by varying length of the beam)

Fig. 20: ABAQUS results for $L / h=10$ with (a) $p=0$, (b) $p=2$ and (c) $p=10$ (by varying length of the beam)

conducted, in which the material model has been user defined by using UMAT, an ABAQUS/CAE subroutine. The results obtained in ABAQUS and analytical model have been found to be in good correlation.

\section{References}

Miyamoto Y, Kaysser WA, Rabin BH, Kawasaki A and Ford RG (Eds.) (2013) Functionally graded materials: Design, processing and applications (Vol. 5). Springer Science \& Business Media

Birman V (2014) Functionally graded materials and structures. In Encyclopedia of Thermal Stresses (pp. 1858-1865). Springer Netherlands

Chakraborty A, Gopalakrishnan S and Reddy JN (2003) A new beam finite element for the analysis of functionally graded 
materials International Journal of Mechanical Sciences $\mathbf{4 5}$ 519-539

Li XF (2008) A unified approach for analyzing static and dynamic behaviors of functionally graded Timoshenko and EulerBernoulli beams Journal of Sound and vibration 318 12101229

Reddy JN (2000) Analysis of functionally graded plates International Journal for numerical methods in engineering 47 663-684

Sankar BV (2001) An elasticity solution for functionally graded beams Composites Science and Technology 61 689-696

Aboudi J, Pindera MJ and Arnold SM (1999) Higher-order theory for functionally graded materials Composites Part B: Engineering 30 777-832

Kadoli R, Akhtar K and Ganesan N (2008) Static analysis of functionally graded beams using higher order shear deformation theory Applied Mathematical Modelling 32 2509-2525

Zenkour AM (2006) Generalized shear deformation theory for bending analysis of functionally graded plates Applied Mathematical Modelling 30 67-84

Filippi M, Carrera E and Zenkour AM (2015) Static analyses of FGM beams by various theories and finite elements Composites Part B: Engineering 72 1-9

Das S and Sarangi SK (2016, September) Static Analysis of Functionally Graded Composite Beams. In IOP Conference Series: Materials Science and Engineering (Vol 149 p. 012138). IOP Publishing

Sina SA, Navazi HM and Haddadpour H (2009) An analytical method for free vibration analysis of functionally graded beams Materials \& Design 30 741-747

Thai HT and Vo TP (2012) Bending and free vibration of functionally graded beams using various higher-order shear deformation beam theories International Journal of Mechanical Sciences 62 57-66

Khan AA, Naushad Alam M and Wajid M (2016) Finite element modelling for static and free vibration response of functionally graded beam Latin American Journal of Solids and Structures 13 690-714

Li SR, Cao DF and Wan ZQ (2013) Bending solutions of FGM
Timoshenko beams from those of the homogenous EulerBernoulli beams Applied Mathematical Modelling 37 70777085

Chen D, Yang J and Kitipornchai S (2015) Elastic buckling and static bending of shear deformable functionally graded porous beam Composite Structures 133 54-61

Nguyen TT, Kim NI and Lee J (2016) Analysis of thin-walled open-section beams with functionally graded materials Composite Structures 138 75-83

Niino M, Hirai T and Watanabe R (1987) The functionally gradient materials Journal of the Japan Society for Composite Materials 13257

Mitra M, Gopalakrishnan S and Bhat MS (2004) A new super convergent thin walled composite beam element for analysis of box beam structures International journal of solids and structures 41 1491-1518

Lee J (2005) Flexural analysis of thin-walled composite beams using shear-deformable beam theory Composite Structures 70 212-222

Lee J and Lee SH (2004) Flexural-torsional behavior of thinwalled composite beams Thin-Walled Structures 42 12931305

Pandey MD, Kabir MZ and Sherbourne AN (1995) Flexuraltorsional stability of thin-walled composite I-section beams Composites Engineering 5321-342

Shadmehri F, Haddadpour H and Kouchakzadeh MA (2007) Flexural-torsional behavior of thin-walled composite beams with closed cross-section Thin-Walled Structures 45 699705

Dong SB, Kosmatka JB, Schulz M and Filippou FG (1999) Generalized Warping Torsion Formulation Journal of Engineering Mechanics 125 1227-1228

Shakourzadeh H, Guo YQ and Batoz JL (1995) A torsion bending element for thin-walled beams with open and closed cross sections Computers \& Structures 55 1045-1054

Haque A (2016) Introduction to Timoshenko Beam Theory. Retrieved April, 2, 2017

ABAQUS/Standard User's Manual, Version 6.10, Vol. 1 (2010)

MATLAB and Statistics Toolbox Release 2010a, The MathWorks, Inc., Natick, Massachusetts, United States. 